\title{
Entre identidades diaspóricas y "argentinidad": poesía afroporteña y nación en Argentina a finales del siglo XIX
}

Natalia Guevara Jaramillo*

Fecha de recepción: 18 de agosto de 2018. Fecha de aceptación: 3 de marzo de 2019

\section{Resumen}

En este texto pretendo abordar las ideas de un grupo de poetas afrodescendientes de Buenos Aires, Argentina, con respecto a su inclusión en el proyecto de nación de finales del siglo XIX. Para ello, parto de las dos investigaciones que considero hasta el momento más relevantes sobre la literatura afroargentina (Lewis, 1996 y Solomianski, 2003). De estos trabajos se deriva un debate sobre dos posibles lecturas de la obra poética afroargentina: por un lado, si ella es muestra de una conciencia afro-diaspórica o, por otro, si evidencia un sentido de "argentinidad". En el texto retomo algunas de las obras citadas por los autores señalados e incluyo otras que no fueron analizadas por ellos, las cuales se publicaron en prensa, folletos o libros que datan del periodo comprendido entre 1865 y 1882.

\section{Among diasporic indentities and "argentinidad": afroporteña poetry and nation in Argentina by late 19th century}

\begin{abstract}
In this paper, I intend to address the ideas of a group of Afro-descendant poets of Buenos Aires, Argentina, regarding their inclusion in the nation-building process by late nineteenth century. To do so, I depart from which I consider the two main investigations on the subject (Lewis, 1996 and Solomianski, 2003). From these studies draws a debate about two possible readings of the writings of Afro-argentine poets: on the one hand, if this literature shows a sense of an Afro-diasporic conscience, or, on the other, if it provides evidence of a sense of "argentinidad". In the paper, I revisit some of the poems quoted by the researchers indicated above, and I include other poems which weren't analyzed by them and were published in newspapers, books o pamphlets from the period between 1865 and 1882 .
\end{abstract}

* Universidad Nacional Autónoma de México (UNAM). Programa de Becas Posdoctorales en la UNAM. Becaria del Instituto de Investigaciones Sociales, asesorada por la Dra. Natividad Gutiérrez Chong. Ciudad de México, México. E-mail: nataguevara@yahoo.com

Palabras clave

nación

literatura

afroargentinos

poesía

Key words

nation

literature

Afroargentinian poetry 
1. Este texto se deriva de mi proyecto de investigación posdoctoral, en el cual me propuse analizar las representaciones sobre los afrodescendientes en varias obras de la literatura argentina decimonóni$\mathrm{ca}$, en especial en varias novelas y cuentos de Esteban Echeverría, José Mármol, Juana Manso de Noronha y Eduarda Mansilla, así como contrastarlas con los testimonios provenientes de la poesía afroporteña, publicados en prensa, libros y folletos. Me interesaba ver de qué manera los poetas afroporteños adherían a los cánones de la poesía de la época para posicionarse en torno a las representaciones hegemónicas difundidas en la literatura de las élites. Las fuentes literarias revisadas datan de la década de 1830 y se extienden hasta 1882 . Además de la lectura de las obras literarias y poéticas en periódicos, libros, folletos y dos compilaciones de literatura afroargentina, revisé una serie de estudios publicados en artículos, libros y tesis que han abordado a los afroargentinos en el periodo estudiado, principalmente los dos libros que orientan el análisis que aquí presento, así como las investigaciones de Andrews (1989), Geler (2007, 2008, 2010, 2011), Navascués (2011, 2017) y Ghidoli (2016), entre otros.

2. Otros trabajos también han rescatado la obra poética y literaria afrodescendiente, en particular Lea Geler (2010) ha hecho una profunda investigación sobre la prensa afroporteña; sin embrago, no profundiza en la dimensión literaria de la obra poética afroporteña, como sí lo hacen Lewis (1996) y Solomianski (2003, 2004, 2005). También son destacables en este sentido las recopilaciones publicadas por Norberto Pablo Cirio (2007, 2009). Estos trabajos también han hecho una gran contribución a la visibilización de los afroargentinos y han permitido complejizar la idea de su “desaparición” de la nación.

\section{Introducción ${ }^{1}$}

Hablar sobre los afrodescendientes en Argentina es hablar sobre una presencia negada en la identidad nacional de los habitantes de ese país. Aunque se estima que a finales del período colonial la población afrodescendiente de la ciudad de Buenos Aires llegaba a un tercio, durante el siglo XIX tuvo lugar un proceso de borramiento que dio lugar a la creación de una idea de nación blanca y europeizada. El sentido común suele atribuir la desaparición de los afroargentinos a su participación en contiendas bélicas, a las epidemias de fiebre amarilla, a la interrupción de la trata esclava y a la llegada de millones de inmigrantes europeos a finales del siglo XIX (Andrews, 1989). Sin embargo, el creciente interés sobre este episodio de la historia argentina ha dado lugar a una serie de investigaciones que, en las últimas décadas, han abordado el complejo proceso de desaparición de los descendientes de africanos y han rescatado la producción periodística, literaria y artística de los miembros de este colectivo (Andrews, 1989; Lewis, 1996; Quijada et al., 2000; Solomianski, 2003; Acree Jr. y Borucki 2008 ; Geler, 2010; Navascués, 2011; Ghidoli, 2016, entre otros). Desde distintas perspectivas, estas obras parecen confirmar el argumento de que la llamada desaparición de los afroargentinos fue un proceso de "aplastamiento de la diversidad" (Geler, 2011: 11). Los trabajos académicos que han abordado la presencia de los afrodescendientes en Argentina han sido clave en otorgar un lugar negado a este sector de la sociedad; no obstante, el tema parece seguir circunscrito a la esfera de la investigación social y de las organizaciones civiles, que continúan insistiendo en la visibilización y el reconocimiento de los aportes de los descendientes de africanos a la nación argentina.

Sin embargo, en la vida cotidiana, muchos argentinos y porteños siguen afirmando que en ese país "no hay negros", que "desaparecieron" o que "murieron" en las guerras y epidemias decimonónicas. Así lo confirmé en mi última visita a la Biblioteca Nacional Argentina, en 2017 cuando, al explicar que buscaba los números que quedan de la prensa afrodescendiente de Buenos Aires, la encargada me miró extrañada y respondió de manera categórica, como dirigiéndose a alguien que, por su extranjería, se habría perdido de un episodio central de la historia nacional: “¡Pero si aquí no hay negros! ¡Todos murieron de fiebre amarilla en el siglo XIX! ¿Usted de dónde es?”.

En este texto, me propongo retomar las lecturas sobre la presencia de los afroargentinos en la literatura de este país. Me interesa, en particular, la obra poética de autores afroporteños en la segunda mitad del siglo XIX, la cual ha sido rescatada y analizada en dos importantes publicaciones: el libro de Marvin Lewis, Afro-argentine Discourse: Another Dimension of the Black Diaspora (1996) y el trabajo de Alejandro Solomianski, Identidades secretas: la negritud argentina (2003)..$^{2}$ A partir de la revisión de las obras poéticas afroargentinas, así como de estas dos notables investigaciones, propongo una reflexión sobre dos posibles lecturas de esta poesía: una que privilegia una mirada diaspórica -como es el caso del trabajo de Lewis-, y otra que propone abordarla desde su argentinidad -tal es el caso de Solomianski (2003, 2004, 2005). Planteo que en la discusión sobre estas dos visiones, es posible hallar elementos de interés para leer la obra poética afroporteña en el marco de la construcción nacional $\mathrm{y}$, en ese sentido, para entrever posturas y preocupaciones de sus autores en torno a su inclusión en un colectivo nacional que se encaminaba hacia el blanqueamiento de sus habitantes.

Para ello, propondré algunos elementos teóricos e históricos a la luz de los cuales abordo la relación entre la literatura, las representaciones que en ella se 
proyectan y la construcción de un determinado régimen de diversidad nacional. Exploraré las lecturas de Marvin Lewis (1996)y Alejandro Solomianski $(2003,2004,2005)$ sobre la poesía afroargentina. Propondré que esta obra poética evidencia, como lo señala Solomianski $(2004,2005)$, elementos que permiten identificar un sentido de "argentinidad" en sus autores, lo cual problematiza la mirada diaspórica propuesta por Lewis. ${ }^{3}$ Finalmente, me propongo revisar varias obras poéticas de autores afroporteños, con el fin de identificar de qué manera se refirieron a África, a su pasado y a su presente nacional por medio de tres temas en común: la educación como medio para alcanzar el progreso y la redención, la exaltación patriótica y la estética romántica.

\section{Afroargentinos, literatura y nación: algunos elementos históricos $y$ teóricos para leer las fuentes literarias decimonónicas}

En la literatura argentina del siglo XIX, los afrodescendientes tendieron a ser representados como seres carentes de agencia racional, manipulables por el gobernador Juan Manuel de Rosas, con una corporalidad animalizada y grotesca y propensos a la delación y al odio hacia los unitarios blancos. Estas representaciones, que no se encuentran aisladas de su contexto, tuvieron lugar en un escenario político de profunda polarización entre federalistas y unitarios, el cual persistió hasta 1852. La cercanía de los sectores populares y de los afrodescendientes con Rosas, así como su inclusión en el mundo de la barbarie federalista, fueron elementos recurrentes en las obras literarias de la época.

En Facundo (1845), Domingo Sarmiento presentaba una visión dicotómica de la sociedad argentina, dividida entre civilización y barbarie, y situaba a los afrodescendientes del lado negativo de la oposición. Este esquema dual y el lugar que los grupos humanos ocupaban en él se convirtió en una forma hegemónica de pensar a la nación argentina. Civilización y barbarie eran conceptos; es decir, vocablos que reunían el conjunto de un contexto socio-político, por ello concentraban experiencias históricas y se convertían en herramientas que sustentaban la acción política (Fernández Sebastián, 2009: 26-27). La civilización y la barbarie fueron clave para la forma en que las élites intelectuales y políticas del siglo XIX imaginaron la nación argentina y la plasmaron en la literatura de la época. El texto, como advierte Palti (2009: 15), no es sólo un reflejo del contexto en el que se produce sino que produce, de alguna manera, su propio contexto. Civilización y barbarie, además de conformar una dicotomía que orientaba la narración de Sarmiento, eran conceptos que entrañaban una visión de la historia, de su movimiento y de la realidad política argentina (Palti, 2009: 57-58).

Este esquema dual se repitió en la literatura de la época. En Amalia, escrita entre 1851 y 1855, José Mármol desarrollaba una trama amorosa entre una joven viuda tucumana y un unitario que intentaba huir de la persecución rosista. Su amor era obstaculizado por la barbarie federalista y amenazado por la delación de los personajes afrodescendientes; ellos también rodeaban a Rosas y complementaban la imagen de una suerte de corte grotesca, donde los negros eran bufones que divertían al gobernador. En Los Misterios del Plata, escrita en 1846, Juana Manso (1899) hizo un retrato similar de los afroargentinos: turbas destructoras que sembraban el terror en Buenos Aires, mazorqueros salvajes y bufones de Rosas. El Matadero (1874), quizá el cuento más famoso de Esteban Echeverría, publicado de manera póstuma en la década de 1870, proponía una alegoría al rosismo mediante la imagen de un matadero porteño donde las mujeres afrodescendientes, vulgares y grotescas, actuaban como animales
3. En este texto me limito a abordar este debate en una parte de la segunda mitad del siglo XIX. No obstante, para una discusión sobre el sentido diaspórico en las identidades afroargentinas durante el siglo XX, ver el trabajo de Adamowsky (2013). 
de carroña. La animalización de los afrodescendientes es evidente en estas obras; sus cuerpos deformes y cercanos al mundo animal reflejaban cualidades morales reprobables. De esta manera, por medio de las representaciones literarias, los afrodescendientes eran situados fuera de un proyecto de nación que perseguía el blanqueamiento y la civilización. Estas representaciones animalizadas de los afrodescendientes habían ido ganando terreno en un contexto de difusión global de las teorías del llamado racismo científico.

Otra forma de representación, que tampoco carecía de problemas, era la de la fidelidad y el servilismo, temas recurrentes en la literatura que se refiere a la época colonial o las gestas patrióticas que dieron lugar a la independencia. Distintas novelas y cuentos de Eduarda Mansilla, Juana Manso de Noronha, Federico Barbará y Juana Manuela Gorriti abordaron este tópico (Navascués, 2011 y 2017) y representaron a los afrodescendientes como criados fieles y dispuestos al sacrificio por su amos, los personajes centrales de los relatos. Así, los descendientes de africanos eran percibidos como seres carentes de agencia y de ambiciones propias, incapaces de vivir al margen de las relaciones serviles entre amos y esclavos, y cuya contribución era facilitar un desenlace feliz para los protagonistas blancos. En general, en la literatura argentina de la época, los esclavizados y afrodescendientes tendieron a figurar como personajes secundarios, relegados a espacios marginales y que no se mezclaban con la sociedad criolla pues formaban "un cuerpo extraño con el que es casi imposible el intercambio, al menos en apariencia" (Navascués, 2011: 152).

Estas representaciones, plasmadas en el campo literario, no fueron ajenas al proceso de construcción de la identidad nacional argentina. Juan María Gutiérrez, considerado como el primer crítico literario argentino, destacó el nexo entre la literatura y el avance de la historia nacional y se preocupó por la utilidad de las letras como vía hacia el "progreso y la libertad de los pueblos", la cual contribuiría a su "recomposición social" (Gutiérrez, 1918: 224). La cercanía entre la literatura y la formación de la nación fue explorada por distintos autores latinoamericanos durante los siglos XIX y XX; basta leer, por ejemplo, algunos de los textos del escritor mexicano Ignacio Manuel Altamirano, quien hablaba de la importancia de la literatura y de la novela en la imaginación patriótica y en la exaltación de las peculiaridades del paisaje mexicano. Esteban Echeverría y José Mármol eran, según Altamirano, pioneros en cantar de una manera auténtica "su América del Sur, su hermosa virgen morena, de ojos de gacela y de cabellera salvaje" (1899: 365). Luego, ya entrado el siglo XX, el ensayista peruano José Carlos Mariátegui (2000: 67-69) hacía coincidir el surgimiento de las literaturas nacionales "con la afirmación política" de dichas naciones, estas literaturas evidenciaban una definición de la personalidad nacional; el caso argentino, carente de las tensiones entre las lenguas indígenas y el español, mostraba una individualidad que coincidía con la personalidad nacional forjada en las décadas previas.

De igual manera, la literatura jugó un papel central en el modelo interpretativo de Benedict Anderson en Comunidades Imaginadas; allí Anderson planteaba que la novela y la prensa proveyeron medios técnicos para la representación de las comunidades nacionales, al generar conciencia de un mientras tanto, un tiempo homogéneo y vacío en el cual la nación se proyecta como una comunidad sólida que avanza en la historia. La literatura, según el autor, juega un papel central en el origen de la conciencia nacional porque permite el surgimiento de nuevas ideas de simultaneidad y de comunidad que, gracias a la imprenta, podían ser reproducidas y difundidas con rapidez. En este sentido, el capitalismo impreso fue un hito clave en el surgimiento de las naciones debido a que los impresos 
cambiaron la representación del mundo, que antes era predominantemente visual y auditiva (Anderson, 1993: 46-73). Más recientemente, desde los estudios culturales y poscoloniales, se ha destacado el carácter textual de las naciones contemporáneas; al respecto, Bhabha (2000: 213) planteaba "estudiar la nación a través de su discurso narrativo" y hablaba de la "emergencia de la 'racionalidad' política de la nación como una forma de narrativa".

Lo que me interesa destacar es que el nexo entre las literaturas decimonónicas y la construcción de las naciones ha sido anotado y abordado desde distintas perspectivas, mostrando que las representaciones difundidas en la literatura permitieron legitimar prácticas de poder y determinados proyectos de nación. Al hablar de representación me refiero, de acuerdo con Hall (2010:447-448, 450), a una conexión entre sentido, lenguaje y cultura que se da en el proceso de producción e intercambio del sentido de los conceptos por medio del lenguaje entre los miembros de una cultura -es decir, la relación entre "cosas", conceptos y signos mediante el lenguaje. El vínculo entre los conceptos y el lenguaje es lo que nos da la capacidad, dice Hall, de referirnos al mundo. Esto implica que el sentido es "construido por el sistema de representación", y no se encuentra en los objetos, personas o cosas, aunque los seres humanos lo fijemos de un modo que llega a parecer natural. De esta manera, las representaciones que se derivaron de las literaturas nacionales no estaban desvinculadas de la realidad sino que, por el contrario, contribuyeron a asignarle sentidos. Por ello, las obras literarias escritas por las élites intelectuales de las naciones decimonónicas hablan de proyectos de nación, de formas de concebir la homogeneidad y la diferencia y, en suma, de estrategias de inclusión o exclusión de la diferencia.

Si bien las élites argentinas estuvieron en una posición privilegiada para difundir sus sistemas de representación en las obras consideradas como el origen de la literatura nacional, no fueron las únicas en tener acceso a la escritura y en plasmar en ella sus visiones de la sociedad. Por el contrario, es llamativa la profusión de publicaciones periódicas afroporteñas durante la segunda mitad del siglo XIX, las cuales han sido estudiadas en profundidad por Geler (2010). El auge de estos periódicos, como lo muestra la mencionada autora (2010:27), tuvo lugar en el marco del surgimiento de un "circuito de prensa y literatura popular", muy activo en Buenos Aires desde las primeras décadas del siglo XIX. Con base en la revisión de 306 ejemplares de prensa afroporteña, Geler evidencia múltiples tensiones internas en torno a la forma de concebir a su propia comunidad y la relación de ésta con un proyecto de nación blanqueador, las cuales se reflejan en debates sobre las formas de asociacionismo, la educación, el trabajo, el progreso o la unión de la comunidad, entre otros temas. A su vez, la autora demuestra que la prensa también jugó un papel importante en el disciplinamiento y en la denuncia de episodios de discriminación hacia los afroporteños (Geler, 2010: 40-53).

La prensa destinaba diversas secciones a la publicación de poesía, aunque este género también fue difundido en folletos, libros y reuniones literarias. La existencia de documentos tan valiosos, escritos desde la mirada de autores subalternos en la sociedad decimonónica argentina, ofrece una oportunidad única para analizar de qué manera estos escritores se concebían a sí mismos como parte de una nación que pretendía construirse con base en la blancura.

En suma, por una parte, las representaciones sobre los afrodescendientes en la literatura nacional argentina dan una idea de cómo las élites de ese país concebían su proyecto de nación, una donde la migración europea facilitara el tránsito a la homogeneidad étnica, racial y cultural. Por otra parte, la existencia 
de registros escritos por autores afrodescendientes permite aproximarse a sus auto-representaciones y a la forma cómo, por medio de ellas, concebían su lugar en una nación que se encaminaba hacia el blanqueamiento. Estas obras literarias son diversas y evidencian fragmentaciones internas entre sus autores, miembros de un colectivo que se distinguía a sí mismo con respecto al resto de la sociedad y que mantenía una "esfera pública" propia donde se ponía en marcha su identidad grupal (Geler, 2010: 32). Este corpus literario situaba a los afrodescendientes como sujetos, más que como objetos del discurso, a la vez que se acomodaba a los cánones literarios románticos de su época. Por ello, la poesía afroporteña es una ventana privilegiada hacia las miradas de sus creadores sobre su relación con la sociedad de su época.

\section{Un debate sobre lo diaspórico y lo nacional en la poesía afroporteña}

En 1996, Marvin Lewis publicó Afro-Argentine Discourse. Another Dimension of the Black Diaspora. Su obra sigue siendo el estudio más completo de la poesía afroargentina. A partir de un marco teórico poscolonial, Lewis se proponía indagar sobre la coherencia de los discursos afroargentinos situando a su obra en el contexto de las corrientes de la literatura nacional. Para Lewis, la "desaparición" de los afroargentinos se vinculaba con su incapacidad de crear y mantener un discurso minoritario efectivo (Lewis, 1996: 4-5). Lewis rescató algunos de los poemas de dos importantes autores afrodescendientes, Mateo Elejalde y Horacio Mendizábal; a su parecer, estas obras aparecían enmarcadas en el movimiento romántico argentino, a la par que reflejaban una "ideología afroargentina" sobre la etnicidad y la clase. En suma, la mirada de Lewis buscaba rescatar los sentidos diaspóricos de estos textos literarios producidos con base en el canon literario de su época e inscribía a los poetas señalados en una corriente de pensamiento e identidad africanista.

Alejandro Solomianski (2003, 2004 y 2005) retomó el trabajo de Lewis y confrontó el "panafricanismo" que el autor asignaba a la obra de Horacio Mendizábal y que, a su parecer, la desconectaría de su contexto argentino; Solomianski proponía que ésta, por el contrario, era una evidencia de la "argentinidad" de su autor; es decir, de una "profunda conexión entre su escritura y el escenario político e ideológico argentino" (2005: 84) del periodo posterior a la caída de Juan Manuel de Rosas, que quedó registrada en la Introducción de su libro Horas de meditación (1869) y en el poema gauchesco Arjentina; este último refleja, según Solomianski, la forma como Mendizábal "se inserta a sí mismo, en tanto autor, dentro de una línea especial de la tradición euro-céntrica de la 'alta cultura'” (2005: 84). Mendizábal escribía, dice Solomianski, desde la otredad más oprimida y desprestigiada en la sociedad de su tiempo, razón por la cual su obra tuvo un fuerte tono de denuncia, incluso demostró una orientación anticlerical y "anarco-socialista". Por ello, aunque poco reconocida, la obra de Mendizábal tiene una gran relevancia en la producción literaria argentina, pese a la negación a la que la condenó el eurocentrismo de los cánones de la época.

De los trabajos de Lewis y Solomianski se deriva una pregunta sobre cómo abordar lo que podríamos llamar el sentido de lo "diaspórico" y de lo "nacional" en la obra poética afroporteña. Aunque el propio Lewis advertía sobre la necesidad de equilibrar ambas perspectivas, su trabajo asignó un papel central a las preocupaciones sociales y étnicas de los poetas afrodescendientes, a la vez que propuso verlos como intelectuales exiliados de su sociedad, que no 
habían creado un sentido de "patria ni tampoco su propia tradición literaria" (Lewis, 1996: 50). ${ }^{4}$

¿Es posible extender la "argentinidad" que atribuye Solomianski a la obra de Mendizábal a otras producciones poéticas afroporteñas? ¿Qué nos dice esta discusión sobre los posicionamientos de los poetas afroporteños en torno a un proyecto de nación que los excluía? ¿Cómo puede este debate aportar a nuestra lectura de la literatura afroargentina? Lo que intentaré argumentar es que la "argentinidad" del trabajo de Mendizábal sería extensible a otras obras poéticas afrodescendientes de la época pues, en su mayoría, ellas no revelan un sentido diaspórico. Este hecho, sin embargo, no anula su valor como tradición literaria propia.

Vale la pena aclarar que, como lo ha apuntado bien Solomianski (2003: 187), esta producción literaria no conforma un corpus homogéneo sino que, por el contrario, evidencia fragmentaciones y contradicciones. De igual manera, Geler (2010) ha mostrado que estas pugnas internas fueron ventiladas en las páginas de la prensa afrodescendiente, en la cual también fue recurrente la demanda de unión. ${ }^{5}$ En cuanto a las diferencias de forma, la producción discursiva afrodescendiente no sólo se limitó a la poesía plasmándose también en géneros como el periodismo -que a menudo abordó las relaciones entre los afroargentinos "consigo mismos y con su ancestría"- y la payada -un género que los acercó a la cultura popular de la época- (Solomianski, 2003: 192-193).

\section{Educación para el progreso y la redención}

Una pista sobre el debate en torno al sentido diaspórico y a la "argentinidad" de la poesía afroporteña la ofrece La Redención, un poema de Mateo Elejalde, uno de los escritores afroporteños más reconocidos de la época. En su obra, publicada principalmente en el periódico La Broma y en la cual se destacan sus poemas amorosos, quizá su trabajo más comprometido y ligado a la situación de los afroargentinos fue este:

Ya sonó la hora anunciada

En que una raza oprimida

Empieza á entrar en la vida

De sublime redención;

Por fin...la pálida noche

Que nuestro cielo cubría

Nos anuncia un bello día

De dulce resurrección.

[...] Sigamos siempre adelante,

No nos detengan barreras,

Y sea nuestra lumbrera

El pensamiento veloz:

Ese alado mensajero

Que cruza espacios y nubes

Y que hasta los cielos sube

Elevando de alma a Dios.

[...] Adelante, sí! Adelante

Cada vez con más constancia

Odio eterno á la ignorancia

Amor á la educación!

A la educación divina

Inestinguible lumbrera
5. Al respecto es ilustrativo el capítulo que la autora dedica a la "Unión imposible" (Geler, 2010: 303-337). 
6. Mateo Elejalde "La redención", La Broma, Año I, Época 6, no 7, 3 de febrero de 1881, p. 2.
Y celeste mensagera

De sublime redención. ${ }^{6}$

En el poema, la redención de la "raza oprimida" adquiere un sentido de temporalidad, en el cual los afroargentinos se enfrentan a un nuevo momento histórico que supone su abandono del pasado. Aunque Elejalde no hacía explícito aquello de lo cual su pueblo debía redimirse, el poema hace pensar en los rezagos de la esclavitud y la africanidad escenificada en candombes y bailes de antaño. Si bien el asociacionismo aparecía ligado a la unión y, por tanto, al progreso de la comunidad (Geler, 2010:304-305), los intelectuales afroporteños tendían a concebir los bailes africanos, su música y sus instrumentos como evidencias de costumbres bárbaras que debían ser erradicadas (Geler, 2010: 103-104, 106). Lewis (1996: 30-34) leía el poema de Elejalde como un "llamado a las armas", un "ejercicio de concientización" y "una reacción a la ideología racista". Sin embargo, aunque es innegable el nexo del poema con la situación de opresión de los afroargentinos, el cambio al que alude está vinculado con la educación y el abandono de la ignorancia, que implicaba también dejar atrás referentes étnicos y de sociabilidad de origen africano.

Geler (2010: 28-29) explica que la prensa afroporteña era valorada por su nexo con el progreso, la civilización y la ilustración. Los periodistas afrodescendientes, explica la autora, concebían la prensa como un medio para lograr el cambio social, por lo cual fueron "intelectuales subalternos". A su vez, la prensa brindaba un espacio para que los lectores publicaran textos relacionados con el "bien común", promovía formas de socialización ligadas a las ideas de progreso y civilización, difundía información sobre actividades comunitarias y abría espacio para la producción artística (Geler, 2010: 36; y Geler, 2008). No es inusual, por ejemplo, encontrar en la prensa afroporteña notas sobre eventos sociales donde se presentaban actividades artísticas y literarias que involucraban a miembros de esta comunidad. Desde una mirada literaria, la obra de Horacio Mendizábal, otro importante poeta afroporteño a quien regresaré más adelante, también establecía un nexo entre las letras y el progreso. En la Introducción de su libro Horas de Meditación, Mendizábal proponía que la poesía era una herramienta que permitiría "levantar de su marasmo á una raza desvalida, condenada á la esclavitud al servilismo, al envilecimiento moral y material" (Mendizábal en Solomianski, 2005: 92).

En este sentido, la idea de la búsqueda del progreso mediante la redención de los afroargentinos no sólo fue un recurso poético en la obra de Elejalde. Por el contrario, la redención parece haber sido un tema recurrente en la literatura afroporteña. Un artículo de 1877, difundido en el periódico El Unionista, se titulaba "La hora de la Redención" y planteaba una distinción rotunda entre el pasado y el presente de los afroargentinos, pues mientras que el primero era identificado con la vergüenza y la tristeza, en el presente y el futuro la "palanca poderosa e inquebrantable de la voluntad y de la inteligencia" los colocaría "a la altura que corresponde en el nivel social a los centinelas avanzados del progreso, a los obreros infatigables de la civilización" (El Unionista 1877: 1). El autor comentaba que, según un pasquín que había circulado hacía poco tiempo, "el hombre de color de nuestro país no poseía LA DIGNIDAD DE LA CONCIENCIA (!), que era un ser depravado, disoluto, en suma una úlcera social" (El Unionista 1877: 1).

Los que asistimos de cerca de la revolución social que hoy se opera; los que conocemos los movimientos que la han generado; los que hemos contribuido, bien que humildemente, con nuestra intelijencia y hemos colocado nuestro 
grano de arena en la obra común, tenemos el derecho de lanzarle al rostro un solemne mentís, demostrándole como se lo ha demostrado la sociedad a quien dedica inpudentemente su libelo, que otro sol, el sol de la civilización, nos alumbra; que la educación la instrucción y la ilustración há ya largo tiempo empezaron su tarea con nosotros y que ella no fue infecunda: es necesario que sepa porque lo ha olvidado, que no somos los de ahora veinte años, y que podia haber dedicado su pasquín a los desgraciados salvajes de la Pampa, puesto que para nosotros ha sonado ya la hora de la redención. ${ }^{7}$

La redención a la que se referían el poema de Elejalde y el artículo de prensa citado se lograría mediante el acceso a la educación; la forma como ésta era planteada como estrategia de progreso y de integración a la nación queda evidenciada en múltiples artículos y debates de la prensa afroporteña. Una nota de 1877 comentaba que la educación de las masas "es el único medio por el cual las naciones alcanzan a ser grandes y felices". ${ }^{8}$ A su vez, la propuesta de creación de una escuela para estudiantes de color no parece haber generado consenso. ${ }^{9}$ Una carta enviada al periódico El Aspirante en 1882 planteaba que tal iniciativa sería "el más grande desatino, que podríamos cometer". El autor de la carta se preguntaba "Porque entonces si los blancos sediendo a la corriente civilizadora que invade el mundo, nos admiten a su lado, reconociéndonos el derecho de ciudadanos libres, hemos nosotros mismos de renunciar a estos preciosos dones escluyéndonos voluntariamente" (El Aspirante 1882: 1-2). En este sentido, aunque la escuela "esclusivista" respondiera a quienes pretendían "cerrarnos el paso" en el sistema educativo, no permitiría la inserción de los jóvenes afroporteños a la corriente civilizatoria nacional al segregarlos de las escuelas públicas. ${ }^{10}$ Como lo explica Geler (2010: 302), la discusión en torno al proyecto educativo giraba en torno a la integración de la comunidad afrodescendiente en la nación y los debates de prensa revelaron que no todos estos intelectuales subalternos pensaban su inclusión a la nación de la misma manera.

La educación, en suma, era vista como parte de la experiencia temporal del progreso. Este término, que expresaba una "nueva época", implicaba una apertura al futuro, uno en el cual el fin del mundo no era un destino inevitable y que, por el contrario, empezaba a concebirse de manera progresiva (Koselleck, 2012: 101-102). El concepto de progreso se popularizó después del siglo XVIIIy, con ello, también se universalizó -es decir, ya no designaba los avances en campos delimitables como la ciencia o el arte sino que se convirtió en un agente universal-; por ello, no sólo fue reivindicado por los autores afroargentinos sino que se tornó un tema clave en la literatura de la época. De manera gradual, el progreso se convirtió en un agente histórico; por tal motivo, según Koselleck, "a partir del siglo XIX sería difícil legitimarse políticamente sin estar a favor del progreso" (Koselleck, 2012: 106-107). De esta manera, los escritores afroporteños, de acuerdo con su época, se valieron de la idea del progreso para concebir las expectativas sobre su comunidad.

Sin embargo, ese progreso estaba fuertemente ligado a la nación y uno de los eslabones de esta unión era la educación pública. El poema de Elejalde y los artículos de prensa dejan entrever que el progreso al que aspiraban sus autores implicaba un abandono de lo africano y la inclusión a la corriente civilizatoria de la nación argentina. En este sentido, la "argentinidad" del poema de Elejalde es evidente, en tanto su visión del progreso mediante la redención de su comunidad la aleja de África y la acerca a la nación argentina, en la cual era posible insertarse mediante el acceso a la educación. De esta manera, el poema
7. "La hora de la Redención", El Unionista, 9 de diciembre de $1877, \mathrm{p}$. 1 ; las cursivas y mayúsculas aparecen en el original.

8. “La Educación”, El Unionista, 9 de diciembre de 1877 , p. 1.

9. Geler (2010: 281-302) dedica un capítulo de su libro a discutir este proyecto educativo.

10. "Sección aparte", El Aspirante, Junio 11 de 1882. 
de Elejalde refleja un sentido de identidad que, en su intento por desligarse del pasado, se proyecta hacia el presente y el futuro.

\section{Nombrar a la patria desde un lugar subalterno}

Horacio Mendizábal fue uno de los poetas afroporteños más prolíficos e innovadores. Su fuerte condena a la religión y a la incoherencia de esta institución a la hora de defender a los más desvalidos es uno de los elementos que hace que su obra parezca adelantada a su tiempo. Mendizábal publicó dos libros de poesía pero el texto introductorio de su segunda obra, Horas de Meditación, es quizá su obra más destacable en tanto denuncia la discriminación e inequidad que padecían los afrodescendientes en la sociedad argentina. Para Mendizábal, los abusos de quienes "se decían discípulos del amor y la justicia" (2005: 91) hicieron que el pueblo despertara y buscara su independencia.

Por fin cesó el infortunio. Fueron bien-aventurados los que lloraban, porque entraron en el reino de los cielos: la patria les abrió sus puertas, cuando sus buenos hijos se levantaron para anonadar para siempre el imperio de los tiranos; y aquellos hijos que erraban solitarios se agruparon en torno al altar de las esperanzas.

Después, vino el perdón y el olvido; pero algunos malos hijos de esa madre tant [sic] infortunada, continuaron sangrando sus, devastando sus campos, amenazados en la oscuridad (Mendizábal, 2005: 91; las cursivas son mías).

En su Introducción, Mendizábal denunciaba la opresión y la discriminación hacia los afroargentinos a partir de la historia de la nación, sin referirse a África o la trata esclava. El poeta se situaba en el territorio de lo nacional para hacer sus denuncias y para describir la situación de subalternidad de su comunidad; en su texto, la nación aparece como la redentora de su pueblo al liberarlo de la esclavitud. Esto no impidió que, en otros poemas, Mendizábal hiciera referencias a sus orígenes étnicos y a la trata. En el poema ¡Dieziocho años!, publicado en su primer libro, Mendizábal hablaba de su paso a la adultez, del "triste llanto" que le apenaba y de la carga de opresión que dejaba en él la experiencia de la esclavización. En su segundo libro, Horas de meditación, Mendizábal evidenció su conciencia de una "experiencia afro-americana" más amplia, al referirse al poeta cubano Gabriel de la Concepción Valdés, ejecutado por su participación en la Conspiración de la Escalera, así como al presidente estadounidense Abraham Lincoln por su intervención para la liberación de los esclavos en ese país (Lewis, 1996: 43-44). Lewis demuestra que los temas de la poesía de Mendizábal se referían a una experiencia común de opresión de los pueblos afrodescendientes en América y, por tanto, remiten a una mirada diaspórica. Sin embargo, esta no es una característica generalizable a toda la obra de Mendizábal pues, como lo demuestra Solomianski (2004: 39), el poeta también fue hábil para desarrollar temas locales en clave gauchesca, como evidencia de su "compenetración [...] con la territorialidad rioplatense". En la obra de Mendizábal, parecen coexistir miradas diaspóricas y de "argentinidad".

Otro ejemplo del uso de referentes patrióticos es el de la Cantata Heroica de Ida Edelvira Rodríguez, de fecha desconocida. Quizá debido a su doble condición subalterna como mujer afroargentina es muy poco lo que se sabe de ella y su trabajo no ha sido abordado en las investigaciones citadas sobre literatura afrodescendiente. Según Cirio (2007: 135), quien la incluye en una antología de literatura afroargentina, Rodríguez descendía de esclavizados, trabajaba como correctora en un periódico de Buenos Aires y publicaba poemas en otro. 
La presencia de las mujeres en la esfera de la poesía afroporteña ha quedado poco registrada puesto que ellas eran, en palabras de Geler (2007: 112), un "grupo subalterno de la subalternidad afrodescendiente (y por ello acallado doblemente)". Pese a ello, Geler identificó a varias poetisas y escritoras que publicaron textos en los periódicos afroporteños La Broma y La Juventud, como fueron los casos de Rosario Iglesias, Felisa Pasos y Celina Riglos, así como los de otras autoras anónimas. Estos textos llevan a Geler (2007: 132) a proponer la existencia de un discurso afrofemenino "de resistencia al discurso hegemónico del rol de la mujer [...] marcado por la crítica y la resistencia de las mujeres a la imposición de los cánones de la domesticidad impulsados desde las élites".

La Cantata Heroica de Ida Edelvira Rodríguez proponía cuatro figuras alegóricas: El patriotismo, el genio de las batallas, la Libertad y la Patria. La esclavitud y la libertad a la que se refería Rodríguez en su Cantata no eran necesariamente la de sus antepasados esclavizados, sino la de la patria que había obtenido su independencia al liberarse de sus colonizadores con un "Soplo purísimo" que quebrantó su "secular cadena". El Patriotismo exclamaba:

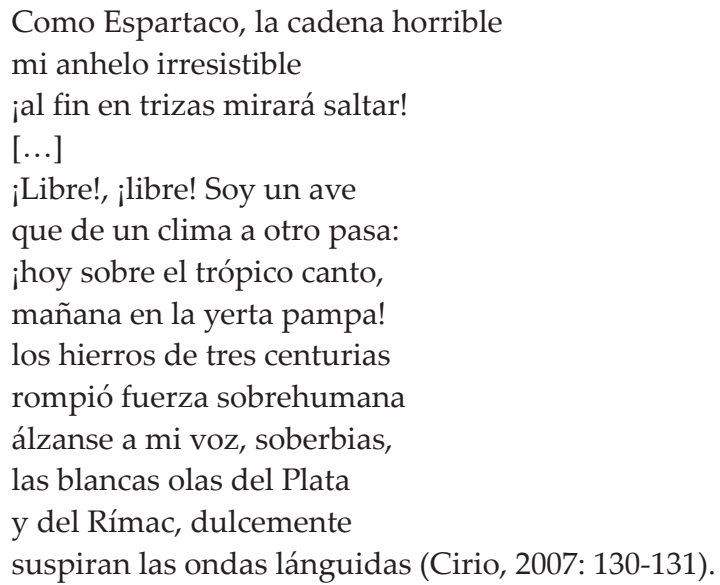

La forma como Rodríguez se refería a la libertad recuerda el uso que adquirió el concepto durante y después de las revoluciones que condujeron a las independencias latinoamericanas. A partir de entonces, las nociones de esclavitud y libertad empezaron a hacer referencia no sólo a la situación de los esclavizados, sino también a la de los americanos con respecto a los peninsulares y a su despotismo. En el transcurso de las revoluciones, la libertad empezó a ser interpretada como libertad nacional; es decir, como el derecho de cada nación a no ser servil a ningún tirano. De esta manera, la libertad empezó a ser concebida como sinónimo de la independencia de la patria, aunque entrara en tensión con la igualdad en sociedades que heredaban jerarquizaciones del sistema de castas desde la época virreinal. Por ello, la libertad política coexistía con la esclavitud (Entin y González Ripoll, 2014: 29-37) que, para el caso de Buenos Aires, permaneció vigente hasta 1860. Luegode las independencias, la noción de libertad también habría empezado a asociarse con el orden -incluido en el proyecto social que representaba la civilización-, mientras que se hizo popular la idea de la libertad civil como el goce de las facultades permitidas por la ley. Esa libertad fue incluida en muchas constituciones latinoamericanas de la época, y la educación era concebida como una de las formas de alcanzarla. Como es evidente, el concepto es polisémico. Lo que me interesa destacar es que, en la Cantata de Ida Edelvira Rodríguez, la libertad y la esclavitud aparecen como conceptos que enmarcan las gestas que condujeron a las independencias, no como testimonios de la situación de esclavizados y afroargentinos. En la 
Cantata, se entremezclan referentes americanos con europeos; entre el Rimac, el Plata, los Andes y la Pampa, aparecen alusiones a deidades griegas como Perseo y Andrómeda y al romano Espartaco. Otra de sus obras conocidas, $\mathrm{La}$ flor de la montaña (1887), publicada en forma de libro, narraba en verso la búsqueda de una flor de leyenda, rara e invisible, en un mundo de hadas, gnomos, céfiros y referentes grecorromanos. Parece como si Rodríguez adoptara un lenguaje literario y poético muy apegado al canon, para que su voz pudiera escucharse en un ámbito predominantemente masculino.

A propósito de la libertad, un poema del mismo nombre publicado por Horacio Mendizábal en su primer libro (1865: 5-6) y citado por Lewis (1996: 36-37), podría también leerse en un sentido patriótico:

\section{$[\ldots]$}

Esa por quien pelearon nuestros padres.

Esa celeste Diosa de bondad,

Esa que amaron tanto nuestras madres

Es la sublime, bella Libertad!

Esa que pisa con su noble planta

$\mathrm{Al}$ déspota, levanta al oprimido

Esa por quien se vierte sangre tanta

Se llama Libertad. ¡Nombre querido!

Vosotros, pueblos oprimidos, lanza

El sacrosanto grito "iLibertad!"....

Que do el cobarde en su terror no alcanza

Llega del noble la heroicidad (Mendizábal, 1865: 5-6).

Para Lewis (1996: 37), la libertad a la que se refiere el poema no sólo se limita a los afroargentinos sino a "las experiencias de los pueblos oprimidos y colonizados en todos los lugares". ${ }^{11}$ En efecto, como lo señalé antes, la libertad hacía referencia a una experiencia amplia, que incluía las luchas por la creación de naciones independientes en América. En otras palabras, aunque el poema no lo hace explícito, es posible que el concepto de libertad al que apela el poeta hiciera una alusión a la historia patria. En este sentido, Mendizábal y otros poetas afroporteños hacían uso del lenguaje social y político de su época, aunque en ocasiones lo adaptaran a su propia situación. La exaltación patriótica fue más evidente en otras obras de Mendizábal, como, por ejemplo, los dos poemas que dedicó a José María Morales, un destacado militar afroargentino (Lewis, 1996: 38).

Un uso distinto del concepto de patria, concebida como lugar de origen de los afrodescendientes y no como sinónimo de la nación argentina, es el que hizo Casildo Thompson en su poema Canto al África (1877). El poema presenta una visión romántica de ese continente, el origen y la patria de los negros esclavizados y sus descendientes, condenados a vivir en el desarraigo.

¿Sabéis cómo se llama

Esa tierra divina y bendecida,

Esa joya que al mundo Dios legara,

Esa púdica virgen ofendida

Que humillada descuella?

Se llama ÁFRICA, sí, 


\author{
África Bella! \\ Es la cuna del negro: esa es la patria \\ Del eterno proscrito que llora \\ Y lejos de sus lares \\ Eleva en patria extraña voz sonora \\ Entonando el cantar de los pesares. (Cirio, 2007: 148)
}

Como en el poema de Thompson, algunos artículos de la prensa afroporteña empezaban a hacer mención de África como lugar de origen, así como a un sentimiento de identificación con otras comunidades de la diáspora afrodescendiente como las que se localizaban en Montevideo o en Brasil -lo cual contrasta con la escasa existencia de referencias a los afrodescendientes de otras regiones de Argentina- (Geler, 2010: 191). Con las primeras, dice Geler, la identificación tenía que ver con la existencia de lazos históricos y redes de contacto existentes con anterioridad, mientras que con las segundas la identificación derivaba del repudio de algunos intelectuales afroporteños a la esclavitud aún vigente allí. En otras palabras, los nexos con otras comunidades de ascendencia africana no tenían como base una conciencia de raza o de origen étnico en común. De esta manera, según Geler (2010: 208), habría surgido un "incipiente sentimiento diaspórico, que en otros sitios de América Latina desencadenaría el afianzamiento de la 'afroamericanidad', y que, sin embargo, en Argentina no se desarrolló".

En este sentido, el afrocentrismo que le atribuye Lewis a la poesía de Casildo Thompson y, en general, a los escritores afroargentinos (1996: 51), no es un atributo generalizado de esta obra poética sino, más bien, una excepción. De ahí lo innovador del Canto al África, fortaleza que le reconocieron incluso algunas lecturas contemporáneas (Cirio, 2009: 128-133). Lewis hace una generalización sobre el afrocentrismo de la obra literaria afroporteña; sin embargo, la poesía sugiere que esta mirada no permeó a toda la escritura afroargentina. En suma, el hecho de que la poesía abordara temas como la discriminación, el racismo o el avance social de los afrodescendientes no implica que su obra girara, de manera mayoritaria, en torno a estas preocupaciones.

\title{
La estética es política: Referentes románticos y cuestionamientos a las representaciones hegemónicas
}

Solomianski (2003: 200) caracterizó a la poesía romántica afrodescendiente por su "refinamiento, la mirada enfocada hacia Europa, la profusión de arpas, liras, laúdes, melancólicas tristezas y amores angelicales". Sin embargo, aunque los poetas afroporteños adoptaron los cánones románticos de su época, su obra se diferencia de las de las élites argentinas en tanto los situaron a ellos mismos dentro de este mundo romántico, que exaltaba el amor, la patria y los sentimientos. En este sentido, aunque la poesía afroporteña puede ser leída como una forma de interlocución con la esfera de la "alta cultura", se diferencia de manera tajante de la literatura producida por las élites en tanto cuestiona o revierte representaciones que mostraban a los afroargentinos como seres grotescos, bufonescos, delatores, sucios y bárbaros. En otras palabras, en la estética que algunas de estas obras plantean hay un posicionamiento político, en tanto el lenguaje poético representa a los afroargentinos como parte de un entorno romántico que los despoja de los atributos negativos que les asignaba la literatura de las élites. Sin embargo, al poner en cuestión las representaciones hegemónicas, los poetas afroporteños no abandonaban el esquema que concebía la sociedad de su época como dividida entre tendencias civilizatorias y bárbaras. 
Como bien señala Lewis (1996: 26-28) con respecto a la obra de Mateo Elejalde, la mitad de sus poemas estuvo dedicada al amor. Para ser aceptado como exponente del romanticismo argentino, dice Lewis, Elejalde tenía que demostrar su manejo de temas y formas clásicos para luego incorporar una dimensión afrodescendiente en su obra. Sin duda, la poesía afroargentina apuntaba a un espacio de la "alta cultura" y de la convivencia con las élites del país (Solomianski, 2003: 192-193); por ello, el manejo del género, así como de las convenciones estéticas y temáticas del canon permitieron que sus autores le hablaran al poder en su propio lenguaje, adscribiéndose, negando o invirtiendo las formas de representación hegemónicas que apuntaban al blanqueamiento de la nación argentina. Si bien el apego al canon permitió a los poetas afroporteños confrontar al poder en sus propios términos, a mi parecer el manejo de la estética romántica revela sus luchas por la inclusión a una nación que se encontraba en el camino hacia la civilización. En este sentido, como lo argumenté con respecto a la obra de Mendizábal y al poema La Redención, Elejalde también parece proponer una estética romántica que se distancia de lo africano, aunque sigue reconociendo una problemática social que aqueja a su comunidad en el marco de una nación que la excluye.

Otra pista al respecto de cómo la estética romántica se convierte en un lente para analizar la relación entre afroargentinos y nación la provee la obra de Miguel Noguera, un poeta casi desconocido cuya obra fue difundida en el periódico Los Negros. Solomianski (2003: 208) parece ser el único autor que ha abordado la obra de Noguera, sobre la cual comenta que habla desde una postura no "proletarizante" que sí asumieron otras producciones escritas afroargentinas y que, de igual manera, situaba a "Los Negros" como "interlocutores afroargentinos válidos [...] frente al resto de la argentinidad 'culta"'. En efecto, en su libro Recuerdos y esperanzas (1870), Noguera no abordó temas antirracistas, problemáticas sociales de discriminación o proyectos de avance social a los cuales se refirieron poetas como Horacio Mendizábal, Casildo Thompson o Mateo Elejalde. Sin embargo, su Himno de la Sociedad Dramática Musical "Los Negros" presenta al grupo aludido desde una estética que, en el contexto de la época, podría ser política en tanto ponía en cuestión las representaciones hegemónicas e inferiorizantes difundidas en la literatura nacional argentina.

El sol cuyos rayos

bañó nuestra cuna

nos ha puesto el rostro

de negro color;

y él es el emblema

de nuestra fortuna,

que siempre á LOS NEGROS

protege el amor.

Escuchad! ya Los Negros elevan orgullosos su himno de honor, porqué sienten latir en su pecho la esperanza, la gloria, el amor.

Se difunde su voz armoniosa como el tierno gemir de un laud, y otra voz de los cielos responde: para siempre á Los Negros salud! [...] 
Las coronas que ciñen su frente de laureles, jazmin y azahar conmemoran los triunfos queridos que jamás se podrán olvidar.

[...]

Nuestros pasos la gloria señala con su huella serena y gentil, esparciendo en su torno el aroma que arrancára al fragante pensil.

Sus destellos desprende á lo lejos que se estienden con dulce fulgor, y no hay rayos mas bellos que eclipsen de esa gloria el brillante esplendor

[...] Hoy Los Negros galantes saludan su existencia risueña y triunfal pues los nobles aplausos del pueblo le presagian un nombre inmortal.

[...] (Noguera, 1870: 30-32).

Según el libro de Noguera, su Himno fue presentado en el Teatro Colón de Buenos Aires en septiembre de 1869 y la música fue escrita por Miguel E. Rojas, a quien Noguera dedica el poema que le precede. En el Himno, los miembros de la sociedad dramática "Los Negros" se definen mediante valores loables como el honor, la esperanza, la gloria y el amor que "laten en su pecho". Ya no son hombres y mujeres grotescos que rodean la esfera pública y privada del caudillo Rosas y que se mueven en un mundo cercano a la barbarie, sino que son galantes y cantan con una "voz armoniosa/como el tierno gemir de un laud". En el canto de Noguera, la corporalidad de "Los Negros" deja de ser la de unos seres animalizados; ellos, en cambio, aparecen coronados con "laureles, jazmin y azahar" que conmemoran sus "triunfos queridos", a los cuales el Himno no hace referencia. Su color de piel, marcador de su origen o cuna, no es aquí abordado como un factor de discriminación sino como "el emblema/de nuestra fortuna". Como señala Geler (2010:309) a propósito de la prensa afroporteña, en este caso Noguera parece proponer sumarse a la nación como comunidad negra, desafiando la blanquitud y su nexo con la civilización.

El uso de la estética romántica para invertir formas de representación negativas de los afrodescendientes también es un recurso que Casildo Thompson utilizó con habilidad en su Canto al África, al cual me referí antes. Aquí, África aparece descrita como "una tierra prometida", "en armonía con el orden celestial", cuya paz es interrumpida por la trata esclava (Lewis, 1996: 56-57). El origen de los afroargentinos y su pasado doloroso era, así, cantado desde una mirada romántica, efectiva para hablarle al poder en sus propios términos. Como en el caso de Noguera, el Canto de Thompson también resalta atributos destacables de los africanos y sus descendientes, revirtiendo las imágenes de sumisión, servilismo y resentimiento que diversas obras literarias de la época le atribuían a los descendientes de africanos.

Bajo un cielo fulgente

de límpido color, con blancas nubes

-como tejidas a las de querubes-,

cielo de millones de luceros

que refulgen en noche de embelesos 
12. El autor se refiere en particular a la obra de Horacio Mendizábal, pero su cita me permite reforzar el argumento que quiero desarrollar en este texto: el hecho de que no sólo la obra poética de ese autor sino la de otros poetas afrodescendientes trazan un nexo con lo nacional más que con una identidad diaspórica. con amante porfía

cariciando la tierra con sus besos.

Bajo un sol de flamígeros colores

que ilumina el espacio en rayos de oro:

con un aire de aromas y un tesoro

en rubíes y perlas de sus flores:

hay una tierra virgen que fue cuna,

por duelo o por fortuna,

de una raza que es mártir por su historia:

raza digna de gloria

porque es noble y altiva

como el león que entre la selva mora,

y que en acerba hora

arrastróla al abismo de la infamia,

¡ah! sin temblar la fratricida mano,

de un bárbaro Caín, cruel, inhumano... (Cirio, 2007: 147).

A mi parecer, la adopción del canon estilístico romántico vincula esta obra poética de manera profunda con su contexto nacional, lo cual permitiría matizar la lectura sobre el aislamiento y el exilio interno que atribuye Lewis a los poemas de Mendizábal y Elejalde. Si la obra poética afrodescendiente es analizada desde una perspectiva de alejamiento de los autores con respecto a su sociedad, es posible, como lo hace Lewis, concluir que no fueron exitosos en crear un sentido de apego a su patria, ni tampoco a su propia tradición literaria. Sin embargo, si preferimos subrayar sus temas y formas estilísticas, lo que sugieren muchas de estas obras poéticas afrodescendientes es una "profunda conexión" con "el escenario político e ideológico argentino" (Solomianski, 2005: $84),{ }^{12}$ así como una habilidad notable para desmarcarse de las representaciones hegemónicas mediante el manejo del lenguaje canónico.

\section{Reflexiones finales}

Una lectura de la poesía afroporteña desde la búsqueda de sentidos diaspóricos o de "argentinidad" permite constatar lo que señaló Geler (2010: 202-204) para el caso de la prensa producida por esa comunidad, a la cual, según la autora, no se le podría atribuir de manera automática una conciencia diaspórica. Lo que pretendo argumentar es que el apego de estos autores al canon, en cuanto al estilo y a los temas abordados, no evidencia un distanciamiento de la sociedad nacional o un exilio sino, por el contrario, un intento por incluirse en la nación argentina y por tener una voz en ella.

$\mathrm{Al}$ analizar esta obra desde un marco decolonial del Caribe, Lewis la aborda desde lo que no fue y no logró para consolidarse como una tradición literaria propiamente afroargentina. La heterogeneidad de posturas evidentes en la poesía y en la producción literaria afroporteña, que evidenciaría una incapacidad de forjar una identidad colectiva (Lewis, 1996: 133) tampoco explica por completo la "desaparición" de los afroargentinos del proyecto de nación. La conexión de esta obra con su contexto argentino, más que con una mirada diaspórica, no le resta el carácter de tradición literaria propia de la comunidad afrodescendiente de Buenos Aires. Por el contrario, reconocer la "argentinidad" de estos textos implica un esfuerzo en restituirles su lugar en la historia y en la literatura nacional. 


\section{Fuentes documentales citadas}

»Altamirano, I. M. (1899). Obras, Tomo I, Rimas-Artículos literarios. México, Imprenta de V. Agüeros.

»Cirio, N. P. (2007). En la lucha curtida del camino... Antología de literatura oral y escrita afroargentina. Buenos Aires, Instituto Nacional contra la Discriminación, la Xenofobia y el Racismo.

»Cirio, N. P. (2009). Tinta negra en el gris del ayer: los afroporteños a través de sus periódicos entre 1873 y 1882. Buenos Aires, Teseo.

»Echeverría, E. (1874), “El Matadero” en J. M. Gutiérrez (comp.), Obras completas de D. Esteban Echeverría, Tomo Quinto: 209-242. J. Buenos Aires, Imprenta y Librerías de Mayo.

» Gutiérrez, J. M. (1918). Estudio sobre las obras y la persona del literato y publicista argentino D. Juan de la Cruz Varela. Buenos Aires, Casa Vaccaro.

» Manso de Noronha, J.P. (1899). Los misterios del Plata. Buenos Aires, Imprenta Los Mellizos.

» Mendizábal, H. (1865). Primeros versos. Buenos Aires, Imprenta de Buenos Aires.

» Mármol, J. (1877). Amalia. Tomos I y II. Leipzig, F.A. Brockhaus.

» Noguera, M. (1870). Recuerdos y esperanzas. Buenos Aires, Imprenta Tipográfica de Pablo F. Coni.

»Sarmiento, D. F. (1999). Facundo. s/l, Ediciones El Aleph.

» Rodríguez, I. E. (1887). La flor de la montaña. Buenos Aires, Imprenta La Sud Americana. 


\section{Prensa}

" Biblioteca Nacional Argentina (BNA)

El Aspirante, 11 de junio de 1882

El Unionista, 9 de diciembre de 1877

La Broma, 3 de febrero de 1881 


\section{Q Bibliografía citada}

" Acree Jr., W. y A. Borucki (eds.) (2008). Jacinto Ventura de Molina y los caminos de la escritura negra en el Río de la Plata. Madrid, Iberoamericana-Vervuert.

" Adamowski, E. (2013). "La dimensión étnico-racial de las identidades de clase en la Argentina. El caso de Cipriano Reyes y una hipótesis sobre la 'negritud' no diaspórica” en Guzmán, F. y L. Geler (eds.), Cartografías afrolatinoamericanas. Perspectivas situadas para análisis transfronterizos: 87-112. Buenos Aires, Biblos.

»Anderson, B. (1993). Comunidades imaginadas. Reflexiones sobre el origen y la difusión del nacionalismo. México, Fondo de Cultura Económica.

»Andrews, G. R. (1989). The Afroargentines of Buenos Aires, 1800-1900. Madison, Wisconsin. University of Wisconsin Press.

"Bhabha, H. (2000). "Narrando la nación" en Fernández, A. (comp.), La invención de la Nación. Lecturas de la identidad de Herder a HomiBhabha: 211-219. Buenos Aires, Manantial.

" Geler, L. (2007). “Nuestro sexo está de pie”. Voces afrofemeninas en la Buenos Aires de 1876-78. Claroscuro 6: 109-137.

” Geler, L. (2008). “'Marcando lentamente la obra de nuestra reorganización’: intelectuales subalternos afroporteños y la construcción del estado nacional argentino a finales del siglo XIX” en Martínez Mauri, M. y E. Rodríguez (coords.), Intelectuales, mediadores y antropólogos. La traducción y la reinterpretación de lo global en lo local: 171-185. San Sebastián, Ankulegi.

"Geler, L. (2010). Andares negros, caminos blancos. Afroporteños, estado y nación. Argentina a fines del siglo XIX. Rosario, Prohistoria Ediciones/TEIAA, Universidad de Barcelona.

" Geler, L. (2011). "Afroporteños: autorepresentaciones y disputas en el Buenos Aires de ayer y de hoy" en Afrodescendencia. Aproximaciones contemporáneas desde América Latina y el Caribe, México DF, Centro de Información de las Naciones Unidas para México, Cuba y República Dominicana. Disponible en Internet: http://www.cinu.mx/ AFRODESCENDENCIA.pdf. Consultado el 15 de abril de 2016.

》 González-Ripoll, D. y G. Entin (eds.) (2014). Libertad, Diccionario político y social del mundo iberoamericano. La era de las revoluciones, 1750-1850, Tomo V. Madrid, Sociedad Estatal de Conmemoraciones Culturales.

" Ghidoli, M. de L. (2016). Estereotipos en negro. Representaciones y autorrepresentaciones visuales de afroporteños en el siglo XIX. Rosario, Prohistoria.

» Hall, S. (2010). "El trabajo de la representación” en Restrepo, E., Walsh, C. y V. Vich, V. (eds.), Stuart Hall,Sin garantías: Trayectorias y problemáticas en estudios culturales: 447482. Bogotá, Pontificia Universidad Javeriana, Universidad Andina Simón Bolívar, Instituto de Estudios Peruanos.

"Koselleck, R. (2012). Historias de conceptos. Semántica y pragmática del lenguaje político y social. Madrid, Trotta.

»Lewis, M. (1996). Afro-Argentine Discourse: Another Dimension of the Black Diaspora. Columbia, University of Missouri Press.

" Mariátegui, J. C. (2000). "El florecimiento de las literaturas nacionales", Fernández Bravo, A. (comp.), La invención de la nación. Lecturas de la identidad de Herder a Homi Bhabha: 67-73. Buenos Aires, Manantial. 
» Navascués, J. (2011). El estereotipo invisible: imágenes del afrodescendiente en la narrativa argentina del siglo XIX. Altre Modernitá 6 (11): 147-162.

» Navascués, J. (2017). “Estereotipo y afrodescendientes en la narrativa romántica argentina (Barbará, Manso, Gorriti)” en Folger, R. y J. E Gutiérrez (eds.), La mirada del otro en la literatura hispánica: 171-194. Zurich, LitVerlag.

»Palti, E. (2009). El momento romántico. Nación, historia y lenguajes políticos en la Argentina del siglo XIX. Buenos Aires, Eudeba/ Universidad de Buenos Aires.

»Quijada, M., Bernand C. y A. Schneider (2000). Homogeneidad y nación, con un estudio de caso: Argentina, siglos XIX y XX. Madrid, Consejo Superior de Investigaciones Científicas.

»Solomianski, A. (2003). Identidades secretas: la negritud argentina. Rosario, Beatriz Viterbo.

» Solomianski, A. (2004). Ensayo y utopía argentina en Horacio Mendizábal. Hispamérica 33 (97): 29-41.

» Solomianski, A. (2005). Horacio Mendizábal: ‘Horas de meditación', ‘Arjentina'. Hispamérica 34 (100): 83-87. 